\title{
A ASSISTÊNCIA ESTUDANTIL NA UNIVERSIDADE DE BRASÍLIA DURANTE A PANDEMIA DO COVID-19
}

\author{
STUDENT ASSISTANCE IN THE UNIVERSITY OF BRASÍLIA DURING THE \\ COVID-19 PANDEMIC
}

Jackeline Soares Lima ${ }^{1}$

\begin{abstract}
RESUMO: Este artigo trata-se de um relato da experiência de trabalho na assistência estudantil da Universidade de Brasília durante a pandemia do Covid-19 em 2020. O período estudado (março a setembro) abrange desde a suspensão do funcionamento presencial no campus universitário, às medidas e planejamento de retomada do semestre e o efetivo retorno do período letivo de maneira remota. O objetivo desse relato é realizar um exame reflexivo das ações desenvolvidas para a promoção da assistência estudantil apontando os acertos, ganhos, dificuldades e demais resultados alcançados. Apresenta o processo de implantação do edital inédito de "inclusão digital" que teve a finalidade de assegurar igualdade de oportunidade e isonomia de participação nas aulas onlines da universidade, proporcionando aos estudantes de baixa renda acesso à internet e computador. Utilizou-se a metodologia de observação participante e análise documental na construção do relato de experiência. Avaliou-se como efetivo as ações desempenhadas e os desafios encontrados deverão ser orientadores para repensar o próximo semestre.
\end{abstract}

Palavras-chave: Relato de experiência. Universidade de Brasília. Assistência Estudantil. Covid19. Inclusão Digital.

\begin{abstract}
This article is an experience report about the work in the student assistance at the University of Brasilia during the pandemic of Covid-19 in 2020. The period studied (March to September) englobes from the suspension of presential operation on the university campus until measures and planning for resuming the semester and the effective return of the term remotely. The main objective is to reflex about the actions developed to promote student assistance and check the successes and difficulties. It shows the process of implementing the unprecedented "digital inclusion" that gave to low-income students oportunity and equality in online classes by way of access to te internet and computers. Participatory observation and bibliographic analysis were the Two methodological procedures useds in this experience report. The work performed was evaluated as effective and the challenges encountered should be guiding to rethink the next semester.
\end{abstract}

Key-words: Experience report. University of Brasília. Student assistance. Covid-19. Digital Inclusion.

${ }^{1}$ Assistente social da Universidade de Brasília. 


\section{INTRODUÇÃO}

Esse artigo tem por objetivo trazer um relato de experiência de trabalho na Universidade de Brasília (UnB) e realizar um exame reflexivo das ações para a promoção da assistência estudantil apontando os acertos, ganhos, dificuldades e demais resultados alcançados. A autora atua como assistente social na Diretoria de Desenvolvimento Social (DDS), setor responsável pela execução dos programas de assistência estudantil na universidade. A partir da sua vivência e perspectiva profissional pretende relatar a experiência do planejamento e implementação das ações excepcionais decorrentes da inesperada pandemia estabelecida. A análise acontece especificamente no período de pandemia do COVID-19, no ano de 2020, nos meses de março a setembro. As atividades desempenhadas no período mencionado, em sua maioria, foram singulares dentro da história do setor e não possuíam parâmetro anterior em que pudessem se basear. As mudanças abruptas trazidas pela pandemia resultaram em mudanças substanciais nos processos de trabalho, para adaptar o acesso à assistência estudantil dentro dos novos moldes de funcionamento apresentados pela universidade.

A presente pesquisa constatou que a criação do edital de "Inclusão Digital", foi a ação inédita que recebeu a maior concentração de esforços, planejamento, recursos humanos e financeiros para ser concretizada. A relevância desse relato se justifica pela memória das atividades realizadas estar documentada, a importância de se iniciar um processo de reflexão das decisões em um contexto atípico, esboçar um início de avaliação de tudo que foi desenvolvido e projetar possibilidades, caso no futuro aconteça eventualidades semelhantes. A metodologia utilizada foi o de observação participante e análise documental. Será apresentado relato e percepções pela ótica da autora enquanto servidora pública integrante do setor estudado. Foram analisados os documentos produzidos no período avaliado (relatórios, processos, atos, e-mails oficiais, notícias etc.) sobre as ações realizadas na UnB relacionadas a assistência estudantil. Sob a perspectiva teórica do método crítico-dialético, também foi realizada a análise de produções teóricas científicas que fizessem interlocução crítica com a política de educação como um direito social.

O trabalho está estruturado em três partes na intenção de situar o leitor na dinâmica envolvida ao se executar a Política de Assistência estudantil na UnB. A primeira parte é dedicada a realizar um resgate histórico da situação política brasileira nos últimos cinco anos, para compreender como a política de educação encontrava-se em 2020. A segunda parte situa sobre o funcionamento e estrutura da assistência estudantil na UnB. E a terceira parte é o relato de experiência de fato. 


\section{CONTEXTUALIZAÇÃO POLÍTICA DE ASSISTÊNCIA ESTUDANTIL 2015-2019}

Antes de iniciar a discussão sobre as atividades desenvolvidas na assistência estudantil no ano de 2020, marcado por mudanças bruscas nas atividades produtivas como um todo, devido à pandemia do Covid-19, é necessário resgatar temporalmente qual a conjuntura que a Política de Assistência Estudantil se encontrava até então na UnB. O período considerado é entre 2015 e 2019, que coincide exatamente com o quinquênio de ingresso da autora na universidade e na diretoria. Nesse período diversas mudanças de ordem social e política aconteceram no Brasil, com influências drásticas nas políticas econômicas e, por consequência, na política de educação. Três presidentes com posicionamentos e inclinações políticas divergentes estiveram no poder e tiveram influência na maneira como a política de assistência estudantil chegou em 2020.

Desde o golpe de Estado $^{2}$ em 31 de agosto de 2016, o Brasil tem vivido sua pior fase desde a Constituição de 1988 (CF 88) e estudos apontam aumento exponencial da desigualdade social. De acordo com pesquisa mais recente do Instituto Brasileiro de Geografia e Estatística (IBGE), os resultados da Pesquisa Nacional por Amostra de Domicílio Contínua (PNAD), mostraram que a diferença entre os rendimentos dos trabalhadores mais ricos e os mais pobres atingiu recorde em 2018 desde o início da série histórica do índice, em 2012. Em 2018, a média do salário mensal recebido por $1 \%$ da força do trabalho foi o equivalente a quase 34 vezes o que a metade mais pobre da população, ou seja, $10 \%$ da população concentra $43,1 \%$ da massa de rendimentos do país.

O governo brasileiro vem há algum tempo buscando se reestruturar diante da crise política e financeira instalada. O Estado é regulador ${ }^{3}$ e utiliza meios como a política fiscal ${ }^{4}$ para agir na economia em prol dos interesses que o orientam. Quando possui orientação mais social e preocupada com a população tende a estimular a economia e amortecer os impactos dos ciclos econômicos (ROSSI; DWECK; OLIVEIRA, 2018). No entanto, quando a orientação governamental está mais inclinada aos interesses das classes capitalistas, as decisões políticas e econômicas tendem a sacrificar a população para benefício e lucro do mercado e dos setores

\footnotetext{
${ }^{2}$ Não há consenso no âmbito da disputa política brasileira em considerar o impeachment da ex-presidenta Dilma como um golpe de Estado. No entanto, a autora decidiu assim chamá-lo por não considerar legítimas as acusações apresentadas e nem a seletividade do congresso diante dessa situação.

${ }^{3}$ O Estado regulador surge no desenvolvimento capitalista, principalmente nos países periféricos, a partir da industrialização tardia. $\mathrm{Na}$ busca de organização política, empresarial e de fortalecimento do capital interno. http://dx.doi.org/10.1590/S0101-33002006000300007.

${ }^{4}$ Política fiscal é uma das formas de se equilibrar a economia em um país pelo governo. Controla-se os gastos orçamentários, estipulando metas e buscando a confiança internacional para atrair investimentos.
} 
dominantes. A política de ajuste fiscal ${ }^{5}$ que tem trazido prejuízo aos mais pobres iniciou-se no governo da ex-presidenta Dilma Roussef de maneira moderada, mas se agravou profundamente após medidas tomadas no governo de Michel Temer, conforme aponta Dweck, Oliveira e Rossi (2018).

O Governo enquanto regulador tem agido em prol da classe dominante, classe que está no topo da pirâmide social, que não representa a maioria da população brasileira, sendo assim atua atendendo aos interesses de poucos e se torna um estimulador da desigualdade social. A política de austeridade implementada por Michel Temer, por exemplo, foi apresentada como “Novo Regime Fiscal”, foi aprovada em 2016 e gerou a Emenda Constitucional 95/2016 (EC 95). Basicamente, essa emenda limita os gastos públicos nas áreas sociais por um período de 20 anos, a despeito do crescimento populacional que o país terá, com a justificativa de economizar dinheiro para o pagamento da dívida pública. Políticas de austeridade são perigosas quando aplicadas pelo governo sob um discurso ludibrioso, onde reduz o Estado, supostamente como única saída para a crise. De acordo com Rossi, Dweck e Oliveira (2018, p.7):

Austeridade pode ser definida como uma política de ajuste da economia fundada na redução dos gastos públicos e do papel do Estado em suas funções de indutor do crescimento econômico e promotor do bem-estar social.

A austeridade produzida pelo governo atende às demandas do mercado e da elite, conforme aponta Rossi, Dweck e Oliveira (2018, p.27) o topo da pirâmide social se beneficia com essas políticas por três motivos:

1) Ao gerar recessão e desemprego, reduzem-se pressões salariais e aumenta-se a lucratividade;

2) O corte de gastos e a redução das obrigações sociais abre espaço para futuros corte de impostos das empresas e das elites econômicas;

3) A redução da quantidade e da qualidade dos serviços públicos aumenta a demanda de parte da população por serviços privados em setores como educação e saúde, o que aumenta os espaços de acumulação de lucro privado.

Indo de encontro à tudo que a CF 88 se propôs para proporcionar ampla cidadania, a EC 95 não é apenas um ajuste fiscal, ela é fruto da retórica neoliberal que repetidamente apresentou para a sociedade a falácia de que a redução dos gastos com demandas sociais era inevitável. A EC 95 impõe um caráter contracionista, reduz o tamanho do gasto do governo central na economia, que pode passar de 19,8\% do PIB em 2017 para em torno de 12,4\% em 2037 (DWECK; OLIVEIRA; ROSSI, 2018). Essa contração impede a manutenção e expansão

\footnotetext{
${ }^{5}$ Os autores se referem a política de ajuste fiscal pautada na austeridade. A partir do governo Dilma, observou-se o início desse tipo de política que tende a sacrificar a população sob a justificativa de economia e/ou falta de orçamento.
} 
dos serviços públicos, visto que não acompanha o crescimento populacional. A EC 95 é um plano de estado mínimo que, no caso brasileiro, traz prejuízos gigantescos para um país que possui desigualdades abissais e onde a distribuição orçamentária é peça fundamental para equilibrar esses abismos.

A educação como um direito teve avanços e retrocessos no decorrer da história brasileira, de acordo com Imperatori (2017), por vezes esteve presente nas constituições e em algumas foi retirada. E, ainda que tenhamos obtido muitos avanços no campo político, principalmente, quando falamos da CF 88, que ampliou os recursos da União para a educação em $18 \%$, a falta de legislação, diretrizes e instrumentos legais que assegurem o financiamento se torna um obstáculo considerável para se pensar a educação enquanto direito social (MACHADO, 2017).

A expansão do ensino, especialmente a expansão do Ensino Superior (ES), possibilitou o ingresso de uma diversidade maior de estudantes, a partir de 1970 ampliou-se o número de vagas trazendo o desafio às instituições federais de ensino de manter esses estudantes via assistência estudantil (IMPERATORI, 2017). A manutenção do estudante na universidade é uma preocupação que exige uma política nesse sentido, pois no Brasil são múltiplos os motivos da evasão. Parte dos impedimentos está relacionado às dificuldades financeiras, mas há outros importantes fatores de exclusão tais como: cor, raça, deficiências, idade, orientação sexual, por exemplo. Criar uma política consistente de assistência estudantil é fundamental para evitar a evasão, pois possibilitaria criar condições básicas de manutenção.

Pesquisa recente da Associação Nacional dos Dirigentes das Instituições Federais de Ensino Superior (ANDIFES) mostrou que o perfil dos estudantes da graduação, cada vez mais tem refletido a realidade brasileira. A diversidade da população no que tange a raça, sexualidade, cultura e renda, tem se mostrado no âmbito acadêmico universitário. A pesquisa mostrou que o número de cotistas subiu de 3,1\% em 2005, para 48,3\% em 2018. No quesito renda, em 1996 44,3\% do corpo discente possuía renda familiar per capita mensal de um e meio saláriosmínimos, em 2018 o percentual representa 70,2\% (ANDIFES, 2019). Esses resultados revelam a importância decisiva que políticas de assistência estudantil possuem ao permitir a permanência de estudantes de baixa renda em um espaço marcado, na história brasileira, pelo pertencimento as classes elitistas.

Mediante essa realidade onde a política de educação é valorizada e desvalorizada a cada governo, um grande marco na política de assistência estudantil é recente, a instituição do Plano Nacional de Assistência Estudantil (PNAES). O programa simboliza a vitória dos movimentos 
sociais que demandaram por anos e tinham o financiamento da educação como bandeira de luta. O PNAES foi instituído em 2007 por portaria normativa do MEC de no 39 e sancionado pelo Decreto 7.234 em julho de 2010, pelo presidente Luiz Inácio Lula da Silva. Possui a finalidade de atender os estudantes matriculados na graduação presencial em Institutos Federais de Ensino Superior (IFES), de baixa renda, viabilizando condições de permanência e diplomação (LEITE, 2015).

No artigo $4^{\circ}$ do PNAES está registrado a intenção de que a inclusão social aconteça pela educação, desta maneira viabilizando igualdade de oportunidades e avanço no desempenho acadêmico para evitar a retenção e evasão. No artigo $5^{\circ}$ fica claro que a prioridade de atendimento são os estudantes provenientes da escola pública ou com renda familiar de até um salário-mínimo e meio per capita. Foi fundamental para se repensar e planejar as estratégias de permanência dentro da assistência estudantil nas universidades de todo país. Importante ressaltar que a maneira como cada universidade irá conduzir suas ações para assegurar os meios de permanência dos estudantes dentro da assistência estudantil é particular e de livre administração pelas IFES (IMPERATORI, 2017).

Outra característica importante do PNAES que o torna importante marco na política de educação é seu caráter de política social. Além de não exigir contrapartida dos estudantes beneficiários ou outra exigência como condicionante para recebimento dos benefícios. Sendo assim, o estudante considerado perfil possui direito de acesso por estar dentro do corte de renda. O PNAES marcou o início dos avanços no campo do financiamento do governo federal no que tange a assistência estudantil, mas não resolveu todos os problemas e possui muitos limites. $\mathrm{O}$ fato de ser focalizado é problemático, pois seu público está dentro de um corte de renda e está sujeito às políticas de retração do orçamento.

A EC 95, juntamente com o descompromisso do governo com a educação tem causado a redução do financiamento da assistência estudantil frente a demanda que cresce a cada ano. $\mathrm{O}$ PNAES que possui um caráter não universalista tem se tornado cada vez mais focalizado. Os recursos que a partir de 2002 estavam em crescimento contínuo, em 2016 decresceu 17\%, ou seja, por um período tivemos avanço na política de assistência estudantil, em seguida entramos em declínio (MACHADO, 2017). Desta maneira, a política vai se afunilando de maneira que dentro do grupo de estudantes considerados perfis de acesso aos benefícios o número de contemplados é cada vez mais restrito por não haver recurso para atender a todos. É a focalização dentro da focalização, os estudantes que acessam os benefícios são os com 
vulnerabilidade socioeconômica mais acentuada, em resumo: a seleção para a assistência estudantil dentro das IFES precisa contemplar entre os estudantes pobres, o mais pobre.

O PNAES por ser sustentado por um decreto e não por uma lei ${ }^{6}$, não é uma política consolidada, está em constante disputa por diferentes frentes com interesses diversos e muitos desses interesses, contrários aos seus princípios. A defesa do PNAES deve ser na direção do combate às desigualdades e, principalmente, na busca da permanência estudantil até sua diplomação. A vigilância e articulação dos atores sociais na defesa e ampliação do PNAES precisa ser ininterrupta, pois a política brasileira é extremamente instável, avançando e retraindo no campo dos direitos.

\section{A ASSISTÊNCIA ESTUDANTIL NA UNB}

Em 1986 foi instituída na UnB a assistência estudantil e posteriormente, em 1994, foi aprovada por intermédio do Ato da Reitoria 266, a estrutura organizacional da DDS (SANT'ANNA, 2019). A diretoria objetiva realizar projetos e ações que viabilizem direitos à educação e cidadania dos estudantes em vulnerabilidade social. Dentro do organograma administrativo da UnB, a DDS encontra-se submetida ao Decanato de Assuntos Comunitários (DAC), assessorando o decanato nos projetos e ações da Política de Assistência Estudantil. Com papel essencialmente executivo, a diretoria é responsável por planejar, implantar, operacionalizar e monitorar o orçamento e ações da assistência estudantil da universidade. A DDS é a maior diretoria do DAC e possui o maior orçamento. Possui seus propósitos alinhados a, já mencionada, Política de Assistência Estudantil que tem a finalidade de ampliar as condições de acesso e permanência dos estudantes de baixa renda no ensino superior e ao seu maior financiador, o PNAES, cujos objetivos são:

Art. $2^{\circ}$ São objetivos do PNAES:

I - democratizar as condições de permanência dos jovens na educação superior pública federal;

II - minimizar os efeitos das desigualdades sociais e regionais na permanência e conclusão da educação superior;

III - reduzir as taxas de retenção e evasão; e

IV - contribuir para a promoção da inclusão social pela educação (BRASIL, 2010)

Atualmente a DDS é descentralizada e possui postos de atendimento em todos os campi da UnB (Darcy Ribeiro - Asa Norte, FGA - Gama, FUP - Planaltina e FCE - Ceilândia) denominados de Serviço de Programas de Desenvolvimento Social (SPS). Sua estrutura é dividia

\footnotetext{
${ }^{6}$ A lei é superior ao decreto e não pode ser contrariada, o decreto, no entanto, pode vir a ser derrubado.
} 
em três coordenações, sendo elas: Coordenação administrativa (CoAd), Coordenação Técnica de Programas de Assistência Estudantil (CTPAE) e a Coordenação Geral da Casa do Estudante Universitário (CGCEU) (SANT'ANNA, 2019). No seu corpo administrativo conta com 15 servidores que ocupam as funções de estatística, administração, coordenação, assistente da coordenação, secretaria executiva e assistência em administração. No corpo técnico conta com 20 assistentes sociais, 03 psicólogos, 02 pedagogas e 01 técnica em assuntos educacionais.

O PNAES financia a maior parte dos recursos da assistência estudantil na UnB atualmente e a DDS administra o acesso dos estudantes aos benefícios. A participação é condicionada a realização de avaliação socioeconômica feita exclusivamente pelas assistentes sociais e acontece após inscrição nos editais lançados semestralmente. Os programas principais disponíveis, conforme descreve (OLIVEIRA, p.136, 2019) são:

1. Programa Bolsa Alimentação: acesso gratuito às refeições do café da manhã, almoço e jantar, nos Restaurantes Universitários (RUs) dos quatro campi da UnB - disponível para os estudantes da graduação e da pós-graduação;

2. Programa Auxílio Socioeconômico (PASeUnB): concessão de auxílio financeiro mensal no valor de $\mathrm{R} \$ 465,00$ - disponível somente para os estudantes da graduação;

3. Programa Moradia Estudantil (PME): contempla estudantes provenientes de outros Estados ou do Entorno do Distrito Federal, em diferentes modalidades: a) Vaga na Casa do Estudante Universitário (CEU): vaga em apartamento compartilhado na CEU/UnB - específico para estudantes da graduação; b) Auxílio Moradia: auxílio financeiro em pecúnia, no valor de $\mathrm{R} \$ 530,00$, para subsidiar os custos com moradia e aproximar o estudante de seu campus de origem - específico para estudantes da graduação; 4. Auxílio Emergencial: consiste em auxílio financeiro no valor de $\mathrm{R} \$ 465,00$ destinado a estudantes que vivenciem situações de dificuldades socioeconômicas emergenciais, inesperadas e momentâneas que coloquem em risco a permanência na Universidade.

A demanda pela assistência estudantil nos últimos 05 anos cresceu exponencialmente e o crescimento do setor não acompanhou o suficiente para lidar com esse aumento da procura, sem sobrecarregar a equipe. A adesão ao Sistema de Seleção Unificada (SiSU) pela UnB, contribuiu para a democratização do acesso à universidade por estudantes pobres oriundos de diversos estados do país. Além disso, a implementação da Lei de Cotas Sociais (Lei $\mathrm{n}^{\circ}$ 12.711/2012 e Decreto 7.824/12) ampliou o número de vagas para estudantes com perfil de acesso à assistência estudantil (SANT'ANNA, 2019).

\section{PROCESSOS DE TRABALHO DURANTE A PANDEMIA DO COVID-19}

Desde quando foi deflagrada a pandemia pelo COVID-19, o mundo inteiro foi surpreendido com a obrigatoriedade de interromper as atividades produtivas nos mais variados setores. No Brasil as ações para contenção da doença tiveram início no mês de março e iniciouse uma crise de saúde pública sem precedentes. A crise atingiu os sistemas educacionais de todos 
país que também tiveram suas atividades paralisadas. Especificamente no nicho da educação muitos debates e disputas pressionando o fim da quarentena, principalmente por parte dos lobistas defensores dos interesses das instituições de ensino privado. Nas IFES observou-se que dentro de suas particularidades, as instituições organizaram-se construindo propostas para assegurar a continuidade das atividades acadêmicas.

A UnB entrou em quarentena no dia 12 de março e permanece até o momento desse estudo com suas atividades presenciais suspensas (algumas atividades administrativas essenciais, permaneceram funcionando presencialmente). O DAC havia criado em 03/03/20 o Comitê Gestor do Plano de Contingência da Covid-19 da UnB (COES), logo em seguida, através do Ato da Reitoria No 0436/2020 o comitê foi vinculado ao Gabinete da Reitora. O objetivo do comitê é realizar ações, orientações e prestar consultoria à Administração Superior da Universidade de Brasília, de forma sistematizada e especializada, acerca de ocorrências relacionadas à Covid-19 na UnB, em consonância com as diretrizes da Organização Mundial de Saúde, do Ministério da Saúde, da Secretaria de Saúde do Governo do Distrito Federal.

Durante todo o período analisado a reitoria esteve em contato com a comunidade acadêmica através do e-mail funcional, disponível para servidores e estudantes e foi um canal importante de acesso às informações das decisões da gestão superior da universidade. $\mathrm{O}$ Conselho de Ensino, Pesquisa e Extensão (Cepe) votou favorável à manutenção da quarentena alinhando-se aos decretos que o Governo do Distrito Federal (GDF) expedia, principalmente no início da pandemia brasileira, nos meses de março e abril. Foi criado com o objetivo de planejar e coordenar as ações de readequação administrativa e acadêmica, mitigar os riscos diretos e derivados da Covid-19 na execução da missão da Universidade de Brasília, o Comitê de Coordenação das Ações de Recuperação (CCAR), por meio do Ato da Reitoria de $\mathrm{N}^{\circ}$ 0557/2020 no dia 06 de maio. Posteriormente, esse comitê foi o responsável pela criação do plano de retomada das atividades acadêmicas.

No fim de março e início de abril o DAC e a DDS enfrentavam o desafio de garantir alimentação aos estudantes participantes da assistência estudantil (PPAES) beneficiários do auxílio alimentação. Como já foi registrado anteriormente, a alimentação na UnB é assegurada com o acesso gratuito ao restaurante universitário, no entanto, com a suspensão do funcionamento imposta, os estudantes estavam em potencial risco alimentar, principalmente aqueles que residiam na Casa do Estudante que fica dentro do campus universitário. A Resolução do DAC 001/2020, a esse respeito, instituiu o Auxílio Alimentação Emergencial, para atender 
os estudantes PPAES nos meses de abril e maio. A previsão orçamentária foi de 2500 vagas e cada parcela no valor de $\mathrm{R} \$ 465,00$. O acesso foi mediante edital lançado no dia 27 de março.

À medida que a quarentena se estendia a Administração Superior da UnB iniciou avaliação do impacto dessa suspensão e a necessidade de medidas adicionais, em diálogo com o Comitê Gestor do Plano de Contingência em Saúde do Covid-19 da UnB e com os diretores das unidades acadêmicas. A manutenção do expediente home office se manteve e os servidores, no caso da DDS, foram consultados por suas chefias imediatas, a pedido do ministério da economia, para saber se estariam dentro do grupo de risco e se já tinham sido acometidos pela doença. Em junho o CCAR, com o objetivo de coletar informações que pudessem subsidiar o planejamento da fase de recuperação da pandemia e elaborar estratégias para dar andamento ao semestre letivo, convocou os estudantes de graduação e pós-graduação, professores e técnicos administrativos para participar de pesquisa para mapear a situação socioeconômica, de saúde e de acesso a recursos tecnológicos.

Os resultados da pesquisa social feita, dentre os diversos dados, apontaram que $6 \%$ dos estudantes não têm acesso a computador ou tablet e 30\% precisam de internet de melhor qualidade para a realização das atividades remotas. Segundo o levantamento, 35,10\% das turmas de graduação do primeiro semestre de 2020 poderiam fazer exercícios domiciliares, o que alcançaria 54,32\% dos estudantes matriculados. Em julho foi aprovada pelo Cepe a retomada das atividades de ensino na instituição. A volta do calendário acadêmico foi programada para o dia 17 de agosto, com atividades realizadas por meio remoto. De acordo com o cronograma aprovado, haveria três semanas de ambientação após a retomada do semestre, até 4 de setembro, para que discentes e docentes se adaptassem ao novo formato. ${ }^{7}$

A partir da decisão da retomada das atividades se tornou imperioso o compromisso da reitoria e de todo o corpo administrativo e acadêmico da universidade no planejamento e garantia de acesso a todos os estudantes às aulas onlines. Poucos dias após o anúncio da retomada do semestre, o DAC lançou o ato de No 027/2020 que instituiu o Programa Auxílio Emergencial de Apoio à Inclusão Digital, que tem como objetivo garantir inclusão digital para estudantes caracterizados em situação de vulnerabilidade socioeconômica, para a retomada remota das atividades acadêmicas do ano de 2020 da UnB. A equipe da DDS que executaria as etapas de planejamento, coordenação, estruturação e futura avaliação. Dois desafios iniciais se destacavam:

\footnotetext{
7 As informações encontram-se disponíveis no site da UnB: : https://noticias.unb.br/76-institucional/4198pesquisa-para-planejar-retomada-do-calendario-da-unb-esta-no-ar https://noticias.unb.br/76-institucional/4203unb-continua-discussao-sobre-retomada-das-atividades-academicas Acesso em novembro e dezembro de 2020.
} 
o tempo curto para planejamento das ações e os recursos financeiros necessários para garantir o êxito do edital que foi o com valor mais expressivo já ofertado pela universidade.

Nesse período boa parte dos servidores da DDS realizaram atividades atípicas e/ou tiveram que desenvolver outras habilidades. Foram criados grupos de trabalho para lidar com as diferentes frentes de ação que a diretoria tinha que cuidar, pois além do planejamento do programa de Inclusão Digital, muitos estudantes demandavam acesso ao auxílio emergencial, atendimento psicológico e outras demandas administrativas e técnicas. Outro desafio que surgiu para a equipe, ao pensar a construção do edital, foi o de criar um programa novo, nunca trabalhado e ponderar variáveis e problemas que poderiam surgir. As reuniões em equipe aconteceram de maneira remota e traziam uma série de problematizações: a universidade terá recursos suficientes para assegurar a compra de equipamento para todos os inscritos? O recurso será oriundo apenas do PNAES? Por quanto tempo será custeada a internet? Como será da comprovação da compra dos equipamentos por parte dos estudantes? Qual o valor mínimo para adquirir um computador? Buscou-se nas demais IFES do Brasil os seus editais para a inclusão digital, até finalmente criar um edital de acordo com a realidade da UnB e do Distrito Federal.

Ainda em julho foi lançado o Edital 002/2020, de Auxílios Emergenciais de Apoio à Inclusão Digital que teria as seguintes modalidades: Empréstimo de equipamento da UnB, Doação de equipamento realizado por pessoa física ou jurídica da universidade ou da comunidade externa, Auxílio financeiro para aquisição de equipamento eletrônico, Auxílio financeiro para aquisição de chip para acesso à internet. O público-alvo do edital precisou ser mais amplo, não poderia ser restrito aos estudantes já participantes da assistência estudantil, pois precisava dar oportunidade aos calouros de 1/2020 e para estudantes não-calouros que não são da assistência estudantil, muitas vezes porque ficaram de fora do número de vagas de editais anteriores e que precisariam desse suporte. Diante disso, mais um desafio para equipe de pensar como fazer uma seleção com estudantes que já possuíam avaliação socioeconômica que, desta maneira, são perfis para acessar a assistência estudantil, concorrendo com outros estudantes que poderiam não ser perfil. Importante ressaltar que "ser perfil" para a assistência estudantil tem como parâmetro o critério do PNAES de renda per capita familiar de até 1 1/2 salário-mínimo. Não haveria tempo hábil para realizar a avaliação socioeconômica de todos os estudantes, visto que a equipe já previa que esse edital receberia grande procura, pois ofereceria bolsa no valor de $\mathrm{R} \$ 1.500,00$ para a compra do computador. Inclusive esse valor não foi divulgado no edital, para tentar minimizar a procura de estudantes que não estivessem realmente em vulnerabilidade social. A solução encontrada foi de utilizar os dados do Centro Brasileiro de Pesquisa em 
Avaliação e Seleção e de Promoção de Eventos (Cebraspe). A instituição é responsável por fazer a análise das cotas sociais para o ingresso na UnB e, também, utiliza o critério de renda per capita familiar de até 1 1/2 salário-mínimo. A maneira que é conduzida essa avaliação é completamente diferente de como é feito pelas assistentes sociais da DDS e por não estar claro como é realizada essa análise não é um dado que a equipe técnica pode assegurar validade, no entanto, foi a única solução encontrada à curto prazo e uma das fragilidades observadas no período.

No decorrer do período em que o edital esteve com as inscrições abertas, a equipe precisou estreitar o contato com as unidades acadêmicas, pois os estudantes que mais precisavam ser contemplados com o edital de inclusão digital, talvez não estivessem informados do lançamento do edital, ironicamente por estarem de quarentena e sem acesso à internet. Na época, inclusive, foi demandado serviço de divulgação na mídia externa, TV aberta, para tentar divulgar o edital de maneira ampliada. A parceria com as unidades acadêmicas, principalmente aquelas que possuem muitos estudantes de grupo vulneráveis, foi fundamental e efetivo, pois elas contribuíram de ir atrás dos seus estudantes. Um exemplo notável foi o da Faculdade UnB de Planaltina (FUP), que tem o curso de Educação no Campo que possui um número expressivo de estudantes quilombolas e boa parte deles residem em quilombos de acesso precário à internet. A intermediação da FUP durante o processo foi fundamental para o êxito de alcançar esses estudantes.

Foram lançados mais dois editais de inclusão digital ${ }^{8}$, após o primeiro e o edital de $\mathrm{n}^{\mathrm{o}} 004$ estava em vigência quando essa pesquisa foi feita. O primeiro Edital $(002 / 2020)$ contou com 2.745 inscrições, o segundo edital (003/2020) com 452 inscrições e o terceiro por estar em curso ainda não teve os dados levantados. O Grupo de Trabalho que estava executando o edital de inclusão digital, após todos os auxílios financeiros terem sido pagos, dedicou-se a organizar a logística de recebimento de doações e entrega para os estudantes. Após o lançamento da campanha "UnB solidária", a universidade recebeu da comunidade externa aproximadamente 50 computadores novos e usados e recebeu a doação de 368 CPUs do Banco do Brasil. Parte desses equipamentos foi enviado pelos Correios para estudantes que durante a pandemia voltaram para suas casas em outros estados do Brasil. Para os estudantes do DF e entorno foi solicitado que a equipe de transporte da universidade realizasse essas entregas. Toda a logística envolveu outros setores além da DDS e sua execução foi a mais rápida dentro dos limites de

8 Editais disponíveis: http://www.dds.dac.unb.br/images/Editais/Edital_001-2020_Auxilio_emergencial.pdf. http://www.dds.dac.unb.br/images/Editais/2020/Edital_Incluso_Digital.pdf Acesso em: outubro. 2020 http://www.dds.dac.unb.br/images/Editais/2020/Edital_unb_dac_dds_003-2020_21-07-2020.pdf Acesso em: outubro. 2020 
servidores e condições materiais disponíveis. E esses limites institucionais não permitiram que todos os estudantes estivessem com um computador desde o primeiro dia de aula, muitos só foram receber o equipamento no meio do semestre. Importante ressaltar que os três editais de inclusão digital não tiveram demanda reprimida, ou seja, todos os inscritos que estavam dentro dos requisitos elencados nas normas dos editais foram contemplados.

\section{CONSIDERAÇÕES FINAIS}

A decisão política pelo corte dos gastos sociais, imposta pela EC 95, significa decidir sobre privação de direitos. Diversas vezes essas decisões são apresentadas como única alternativa ou como ação inevitável para o reestabelecimento e crescimento econômico. No neoliberalismo o discurso de que o ensino público está falido e de que o Estado não tem condições de oferecer educação de qualidade, é fundamental para que a privatização do ensino gere lucro para os monopólios que dominam esse nicho no mercado capital. A educação superior foi uma das áreas mais atingidas pelas políticas de austeridade adotadas no governo Temer.

O cenário político nacional impactou no alcance da assistência estudantil na UnB. Nesse período já mencionado, entre 2015 e 2019, saímos de um cenário, em 2015, no qual a totalidade de estudantes demandantes pelo acesso aos programas da assistência estudantil foi atendida, para em 2018 e 2019 termos uma demanda reprimida em todos os programas, exceto o programa de Alimentação. ${ }^{9}$

A ideia de realizar esse relato de experiência surgiu da necessidade de iniciar um debate e resgatar as ações realizadas pela assistência estudantil da UnB mediante um acontecimento inesperado, a pandemia do COVID-19, que mudou o curso de funcionamento das atividades acadêmicas e administrativas. O relato também contribuiria para repensar e refletir as práticas do ofício cotidiano e no caso, da implementação do programa de inclusão digital na universidade, avaliar as novas demandas, processos criados e destacar aquilo que foi efetivo ou não, o que deveria se repetir ou ser melhorado. A perspectiva de análise foi feita por uma servidora que compõe o quadro funcional da DDS e que atua como assistente social. Esse relato não será finalizado nessa pesquisa, mas pretende ser aprimorado, levantar mais dados e poder ter uma avaliação mais completa sobre a trajetória do primeiro semestre letivo realizado de maneira remota.

\footnotetext{
${ }^{9}$ Essas informações foram retiradas de análise feita no relatório de gestão da UnB de 2015 e 2018. http://www.dds.dac.unb.br/images/Relatorios-DDS/RELATRIO-DE-GESTO-DA-DDS-2015.pdf http://www.dds.dac.unb.br/images/Relatorios-DDS/Relatrio 2018.pdf Acesso em dezembro de 2020.
} 
Considerando o momento atual da pandemia, as incertezas sobre quando a vacinação alcançará toda a população e a impossibilidade de a universidade retomar as aulas presenciais sem colocar os estudantes, professores e técnicos em risco de saúde, a equipe da DDS compreende que o edital de inclusão digital será permanente enquanto a UnB funcionar de maneira remota. Desta maneira, esse relato de experiência também objetiva dar início as discussões e avaliações de como a assistência estudantil assegurou direitos durante o advento da pandemia, para planejar e melhorar suas ações em futuras situações inesperadas e para aprimorar os próximos editais.

Avalia-se como positiva a implementação do programa de inclusão digital, inclusive, comparativamente com editais de outras IFES, o edital da UnB foi um dos mais robusto e abrangente. Dentre os desafios encontrados, percebeu-se a necessidade de maior proximidade da universidade com os estudantes para compreender suas necessidades. Uma maior proximidade da alta gestão com a diretoria para ouvir dos servidores, que lidam diariamente com a execução da assistência estudantil, suas opiniões técnicas, a necessidade de ampliar o corpo técnico para atender a alta demanda e não comprometer a saúde dos seus servidores com a alta carga de trabalho.

\section{REFERÊNCIAS}

ANDIFES. V Pesquisa nacional de perfil socioeconômico e cultural dos (as) graduandos (as) das IFES. Brasília, 2019. Disponível em: http://www.andifes.org.br/vpesquisa-nacional-de-perfil-socioeconomico-e-cultural-dos-as-graduandos-as-das-ifes-2018/. Acesso em: XX out. 2020.

BRASIL. Decreto n. 7.234, de 19 de julho de 2010. Dispõe sobre o Programa Nacional de Assistência Estudantil - PNAES. Disponível em: <http://www.planalto.gov.br/ccivil_03/_Ato2007-2010/2010/Decreto/D7234.htm>. Acesso em: outubro de 2020.

DWECK, Esther; OLIVEIRA, Ana Luíza Matos de; ROSSI, Pedro (coord.). Austeridade e retrocesso: impactos sociais da política fiscal no Brasil. São Paulo: Brasil Debate e Fundação Friedrich Ebert, 2018. E-book. Disponível em: https://brasil.fes.de/detalhe/lancamento-dapublicacao-austeridade-e-retrocesso-impactos-sociais-da-politica-fiscal-no-brasil. Acesso em 20 de mar. 2020.

IMPERATORI, Thaís Kristosch. A trajetória da assistência estudantil na educação superior brasileira. Revista Serviço Social e Sociedade, São Paulo, n. 129, p. 285-303, maio/ago. 2017. Disponível em: http://dx.doi.org/10.1590/0101-6628.109. Acesso em: 20 de mar. 2020. 
LEITE, Josimeire de Omena. As múltiplas determinações do Programa Nacional de Assistência Estudantil - PNAES nos Governos Luiz Inácio Lula da Silva. 2015. Tese (Doutorado em Serviço Social) - Universidade Federal de Pernanbuco, Maceió, 2015.

Disponível em: https://repositorio.ufpe.br/handle/123456789/16251. Acesso em: 10 de abril de 2020.

MACHADO, Fernanda Meneghini, Financiamento da assistência estudantil nas Universidades Federais. Temporalis, Brasília, ano 17, n. 33, jan./jun. 2017. Disponível em:

https://periodicos.ufes.br/temporalis/article/view/15560. Acesso em: 12 de abril de 2020.

OLIVEIRA, Etiene de Sousa Lima de. Acesso e permanência de cotistas na Universidade de Brasília: estratégias para democratização da educação superior 2019. 250 f., il.

Dissertação (Mestrado em Educação) — Universidade de Brasília, Brasília, 2019. Disponível em: https://repositorio.unb.br/handle/10482/37541. Acesso em: 05 de fev. 2021

ROSSI, Pedro; DWECK, Esther; OLIVEIRA, Ana Luíza Matos de (coord.). Economia para poucos: impactos sociais da austeridade e alternativas para o Brasil. São Paulo: Autonomia Literária, 2018. 375 p.

SANT'ANNA, Marcia Costa de. Assistência estudantil: a percepção dos assistentes sociais sobre seus processos de trabalho na UnB. 2018. Dissertação (Mestrado Profissional em Gestão Pública) - Universidade de Brasília, Brasília, 2018. Disponível em: https://repositorio.unb.br/handle/10482/34941. Acesso em: 15 de nov. 2020 